\title{
DOBLE FACETA LITERARIA DE FRAY VICENTE MARTINNEZ COLOMER
}

E1 siglo xvir tuvo en Valencia una intensa cultura, tan notable como la había tenido en los siglos anteriores y tan expansiva que marcó el sello canto en toda Esspaña como en el extranjero. Para explicar dicha centuria deben considerarse los años ya pasados de los reinados de los Reyes Católicos y sus sucesores. El nombre de Luis Vives basta y sobra para demostrar la veracidad de mi aserto; pero quiero destacar un episodio ya señalado por el P. Torró, rechazado verbalmente por Bonilla San Martín, mas corroborado por la realidad. Hubo un alboroto entre los estudiantes de la Universidad, por preferir las enseñanzas de Vives a las de otros profesores, y preguntado el valenciano sobre qué enseñaba, contestó que lo aprendido en la Universidad valenciana, explicado por sus maestros Jerónimo Amiguet, de quien aprendió Arte Gramática, Retórica y Latinidad; Daniel Sisó, llamado por Vives "Vir bonus et gravis Theologus", y del que se guarda un ejemplar del Gramaticale Compendium en la Biblioteca Pública de Zaragoza ${ }^{1}$. Otro nombre debe añadirse a los citados: el de Bernardo Villanova Navarro, profesor de griego. Admitido lo dicho, adquiere gran relieve el filósofo como amante de su Patria, a la que siempre llamó mi Valencia, y como enaltecedor de su Universidad entre todas las Universidades ${ }^{2}$. La humildad de aquellos que, por no salir de su rincón natal, dejaron un tanto oscuro su nombre, no debe movernos a negar

1 Bonilla San Martín, Luis Vives y la Filosofía del Renacimiento. Madrid, 1903, página 583. (Hay segunda edición.)

2 La ausencia del filósofo no implicaba desprecio por su ciudad natal; antes bien, tenía Vives sobrados motivos para no regresar a las márgenes del Turia. La bibliografía, en la que destacan los nombres de Amador de los Ríos, Américo Castro y otros, se ha enriquecido con la obra del P. Mrguel de la Pinta y J. M.a DE PALACIO, quienes han documentado las vicisitudes familiares ocasionadas por la ascendencia judaica del valenciano. Procesos inquisitoriales contra la familia de Vives. Madrid, 1964, C. S. I. C., vol. I. 
la valía dejada patente por el autor de Institutione feminae christianae. Con el tiempo, sí se acentuó la expansión de los profesores valencianos, y así pudo apuntar don Vicente de la Fuente: "En general fueron teólogos y canonistas los que obtuvieron cátedras en Universidades extranjeras, pocos legistas y algún que otro médico y filósofo. Las Universidades más frecuentadas por españoles y, por tanto, donde éstos pudieron distinguirse más, fueron las de Bolonia, París, Montpeller y Tolosa " ${ }^{3}$. Cada comarca tenía sus inclinaciones y, especialmente, los de Burgos y Valencia se dirigieron a París. A Ortí Figuerola debemos el conocimiento de los nombres de varios profesores, tales como Francisco Escobar y Vicente Blas García, que actuaron en la Universidad de la Sapiencia, de Roma; Juan Gélida, Fray Gregorio Arcís, así como el ya citado Fray Escobar, en París, y Gélida, después, en Burdeos; Juan Luis Vives, en Lovaina; Jerónimo Muñoz, en Ancona; Andrés de Exea, en Montpeller; el Obispo de Orihuela, Ilustrísimo señor don José Esteve, en Sena; el médico doctor Miguel Vilar, en Nápoles, y otros. Es curioso el caso de Vicente Blas García, nombrado para la cátedra de Retórica, de Bolonia, pero, designado también para la misma cátedra en Valencia, prefirió quedarse en la ciudad del Turia, declinando la honra que suponía la elección hecha por la Universidad boloñesa ${ }^{4}$.

Los siglos XVI y XVII vieron crecer los colegios valencianos; Santo Tomás de Villanueva, San Juan de Ribera, Na Monforta y otros probaron su amor a la cultura fundando gloriosas instituciones, muchas de las cuales subsisten todavía. Del siglo xviri es la fundación de las Escuelas Pías, pero en este tiempo hubo una gran conmoción política en el Levante español. Essclapés de Guilló sintetiza, en su Resumen historial de la fundación y antigüedad de la Ciudad de Valencia de los edetanos, vulgo del $C i d_{1}{ }^{5}$, los anales siguientes: “1701. Entra en España D. Felipe V a governar la Monarquía, i Valencia celebra su Coronación. 1705. A 19 de Deciembre cae esta Ciudad en poder del Archiduque de Austria. 1707. A 8 de Mayo, dia de la Santíssima Virgen de los Desamparados, buelve esta Ciudad al deseado dominio del Rei, en resulta de la vitoria de Almansa, que sucedió a 25 del mes antecedente. 1719. Transita por esta Ciudad, Viernes, a 5 de Mayo, el Rei N. S. D. Felipe V, la S. Reina doña Isabel Farnese, i el Príncipe Don Luis i son cortejados con solemníssimas fiestas.) No se puede prescindir de los datos recientemente publicados proce-

3 Historia de las Universidades. Madrid, 1885, vol. I, cap. XV, pág. 144.

4 Ob. cit., II, cap. XLI, págs. 211 y 212 ; Boxilla, Ob. cit., nota 33, I, pág. 585.

5 Valencia. Antonio Bordázar de Artazú. Año 1738, págs. 172 y 173. 
dentes del Archico Municipal de Nules, y dan a conocerlos seis privilegios reales conservados en el referido Archivo: 1708, Felipe V, confirmación de privilegios de la villa $\mathrm{y}$ honor de Nules; 1708, Felipe $\mathrm{V}$ concede el título de Fidelísima a la villa y honor de Nules; 1708, Felipe V concede quince días de ferias; 1708 , Felipe $\mathrm{V}$ concede mercado franco los miércoles; 1709, Felipe V concede a Nules el título de Muy Leal Villa; 1709 , Felipe $\mathrm{V}$ concede la divisa para las armas de la villa ${ }^{6}$.

Temas de gran interés brindan los nombres de Ausias March, Ruiz de Corella, Mosén Febrer, Gil Polo, y ya se repite, por culantos estudian la materia, que Lope encontró en Valencia fucnte copiosa donde bebió los cimientos de su arte.

Pero me interesa ahora centrar el comentario en el siglo xvin, al que pertenecen escritores tan dignes de nota como Fray José Manuel Miñana, trinitario calzado, continuador de la Historia de Estaña del P. Mariana en su versión latina; el Dean de Alicante, don Manuel Martí Zaragoza, residente durante mucho tiempo en Roma protegido por el Cardenal Sáenz. de Aguirre, favorecido también por el duque de Medinaceli, don I uis de la Cerda, cultísimo conocedor de la Numismática, imitador de Góngora gran excavador del Teatro de Sagunto, anotador de la Bibliotheca Y'ctus de Nicolás Antonio y dominador de las lenguas clásicas y otras cuestiones que le dieron justa fama por Europa; don Agustín Sales; el ingenioso Antonio Eximeno; los bibliógrafos Fray José Rodríguez trinilario calzado, a quien debemos la conservación de datos propios de biblióecas particulares desaparecidas hace luengos años; el presbítero don Vicerte Ximeno; el paciente don Justo Pastor Fuster; el activo don Francisco Cerdá y Rico, estudiados estos dos por el señor Almela y por el señor Cronzález Palencia, respectivamente. No debe olvidarse que en este ticmpo vivía también don Juan Bautista Muñoz y Ferrandis, que salió de Valencin en 1770 por haberle nombrado Carlos III Cosmógrafo Mavor de Indias. Esta expansión cultural valenciana en el siglo xviri, apenas esbozada en la fácilmente ampliable relación anterior, rebasa toda especulación crítica por e! vasto horizonte que domina ${ }^{7}$. Para demostrar lo extenso de la materia, hastará añadir, a los nombres citados, los de don Gregorio Mayans

6 Vid. BSCC, octubre-diciembre 1964, tomo XI, cuad. IV, pág. 269. Archivos de la provincia de Castellón inventariados por don I uis Revest y Cormo en 1925. Como se ve, aprovechó Felipe $\mathrm{V}$ todas las ocasiones que se le ofrecieron para otorgar mercedes a aquellos a quienes les había privado de las fundamentales.

7 Años ha abrigué el propósito de estudiar esta materia, y tengo rennidas copinsas notas; empero, no está el ánimo tenso, y temo que ha de quedar mi deseado libro entre los pliegues de un anhelo que no alcanza la realidad. 
y Siscar y el de su protegido en las oposiciones a la Universidad de Salamanca, don Francisco Pérez Bayer. Ambos produjeron una selecta y extensa bibliografía que abarca desde lo epigráfico hasta la revisión crítica, tanto renovando la obra de Nicolás Antonio como impugnando a los falsos cronicones y a los falsificados plomos granadinos debidos a Martínez Conde. Tamaño fue lo acometido por los dos eruditos que, en gran parte, quedó incompleto, como sucediọ con la edición de las Obras de Luis Vives, iniciada por don Gregorio y terminada por su hermano Juan Antonio ${ }^{8}$.

Con objeto de sintetizar lo posible, en esta ocasión me limito a considerar algunos puntos de vista acerca de un modesto escritor, poeta, costumbrista, historiador, novelista con características muy dignas de tenerse en cuenta : me refiero al franciscano Fray Vicente Martínez Colomer, inspirador de juicios breves y elementales. E1 Marqués de Valmar ${ }^{\circ}$ destaca la intención de imitar el Persiles y Sigismunda en Trabajos de Narciso y Filomela; el cervantismo del P. Martínez Colomer se muestra en sus Novelas ejemplares. En El impio por vanidad y El Valdemaro pretende propagar sanos principios, no tan certeramente que no se haya dicho de esta fultima novela "está justamente olvidada". Y es que el cervantismo del franciscano resulta sencillamente externo : El Valdemaro está más cerca de Montengón que del Príncipe de los Ingenios Españoles. En esta novela no falta algún rasgo derivado del Obispo de Mondoñedo: "La vida feliz del campo, aunque al parecer nada brillante como la de la corte, es preferible a la turbulenta que llevan los que están constituidos en altas dignidades.) Las huellas de Cervantes son frecuentemente literales; así, en $R e$ flexiones sobre las costumbres, se lee al tratar de las comedias: "i Y qué gusto no era ver entonces en la primera jornada un niño recién nacido, ya se ve, como que acababa de nacer en aquel mismo instante, $\mathrm{v}$ verlo en la tercera jornada hecho ya un mozo barbado !) Rasgos todos ellos, en suma, que ponen de manifiesto el sistema literario en la juventud de este religioso, reflejo fiel de las lecturas que hiciera por aquellos días. No tuvo nunca extraordinaria inventiva, más acentuada la intrascendencia en sus primeros tiempos. Se refirió a jornadas más tardías cuando afirmó Valmar: "Apartado del mundo por sus continuas dolencias y por su carácter retraido, prevalecieron, como era natural, en su ánimo, sobre todos los de-

8 El renombre de don Gregorio sigue tan firme que don Lorenzo Riber aceptó su edición vivista como definitiva, $y$ con este criterio emprendió la tarea de traducir la obra del filósofo valenciano. Tuve ocasión de advertirle el error, y he de agradecer al que fue gran amigo la amabilidad con que acogio mi advertencia.

- BAE, Poetas líricos del siglo XVIII, LXI, pág. CXCIX. 
más. los sentimientos de la religión y de la patria. Su inspiración es, en general, tibia y amanerada; pero, a veces, en su sencillo estilo, expresa ideas que llevan el sello de un alma sincera y creyenten ${ }^{10}$. Algo confusas resultan las palabras del $\mathrm{P}$. Blanco García por tratar como monocorde a la musa del poeta, cuando, si ofrece interés, es por su evolución ${ }^{11}$.

Nacido en Beniflá el día 25 de enero de 1763, ingresó en la Orden franciscana; vistió el hábito de religioso observante en el convento de San Francisco, de Valencia. Se dedicó a las Humanidades, una vez que hubo acabado sus estudios en el noviciado, y parece que inició su labor literaria componiendo algunas poesías. Fue destinado al convento de Santa María de Jesús, situado en el actual camino del cementerio, con la nota histórica de haberse instalado allí el manicomio, cuando vendió el innnueble a la ciudad don Gaspar Dotres en 1866, después de haber tenido en dicho edificio, adquirido cuando se extinguieron las órdenes religiosas, una fábrica de hilaturas de seda. Se le nombró Cronista de la Provincia y murió en Valencia el día 22 de febrero de $\mathbf{1 8 2 0 .}$

Sus obras son bastante raras, algunas de muy difícil hallazgo, y otras se han perdido sensiblemente. Pastor Fuster menciona las siguientes (Vid Biblioteca valenciana, II, págs. 414 y 415):

1. Vaticinio del Turia sobre el reinado de Carlos $I V$, acontecido en el tiempo que la muy noble, leal y fidelísima Ciudad de Valencia celebraba su real proclamación, en verso. Valencia, por Salvador Faulí, 1789; en $4 .^{\circ}$ En la edición de las Poesías, de 1818, se anota : "E1 Vaticinio del Turia; la primera producción que dio el autor a luz; pero no ha podido encontrarse ningún egemplar (sic) para poder reimprimirla.)

2. Nueva colección de novelas ejemplares por doña Francisca Boronat y Boria. Se compone de las siguientes: La Narcisa. La petimetra pedante. La Dorinda. El hallazgo de Alejandrina. Valencia, por José Estevan y Cervera, s. a.; en $\mathbf{8 .}^{\circ}$

10 Ob. y pág. citadas.

11 «Es más de loar el buen intento que la ejecución de las composiciones religiosas del P. Vicente Martínez Colomer, cultivador fácil del género, pero a la manera que podía esperarse de un talento nada extraordinario y dirigido por la tradición artística del siglo áltimo, tan estéril como doctamente razonadora. Maneja Colomer el romance con relativa destreza, y hasta al hexasílabo logró darle la rapidez y armonía de que carece en muchos de nuestros buenos poetas. Si él no llegó a merecer este título, supo a lo menos emplear noblemente sus facultades, manteniéndose aislado del tumultuoso movimiento que todo lo trastornaba en derredor suyo.) La Literatura española en el siglo XIX, por el P. BLANco García. Madrid, 1909, tomo I, pág. 45. 
3. El impio por vanidad. Valencia, por dicho Estevan, 1792; en 8." Puso el poeta su nombre por primera vez al frente de esta obra; antes, o lo había ocultado o había empleado el pseudónimo. Én 1805 reimprimió Benito Monfort las ocho novelas anteriores en un volunen.

4. El Valdemaro, por Fray Vicente Colomer. Valencia, por José Ėstevan, 1792; en $8 .^{\circ}$ Nuevas ediciones se debieron a José Orga en 1819 y 1816 , las dos en $12 .^{\circ}$, y por Miguel Domingo, 1822 , en $8 .^{\circ}$, siempre en dos tomos.

5. Explicación ascética del Padre Nuestro, traducida de la que compuso en latín San Buenaventura, por un religioso. Valencia, por Salvator Faulí, 1796; en $8 .^{\circ}$

6. Espejo de disciplina, o tratado de educación para religiosos; compuesto en latín por San Buenaventura y traducido nuevamente por el P. Fr. Vicente Colomer. Valencia, por Salvador Faulí, 1798; en $8 .^{\circ}$

7. Carta a un amigo sobre la elocuencia del púlpito. Anónima. Valencia, por Faulí, 1801 ; en $4 .^{\circ}$

8. Odas a la venida de sus Magestades (sic). Valencia, por Faulí, 1802, en $8 .^{\circ}$

9. Historia de la Provincia de Valencia de la regular observancia de S. Francisco. Tomo I. Valencia, por Salvador Faulí, 1803 ; en $4 .^{\circ}$

Sólo se imprimió este tomo; el segundo trataba de los hechos particulares correspondientes a cada convento, y el tercero se refería a las vidas de quienes ilustraron a la Provincia con sus virtudes o su ciencia; mas quedaron manuscritos por falta de medios económicos para su impresión.

10. Vida perfecta, escrita por San Buenaventura y destinada a las religiosas, y traducida al español. Valencia, Salvador Faulí, 1804; en 8."

11. El Filósofo en su Quinta, o relación de los princinales hechos acontecidos desde la caída de Godoy hasta el ataque de Valencia. Va encia, MDCCCVIII, en la imprenta de Salvador Faulí. Con licencia; $4 .^{\circ}, 34$ páginas.

12. Sucesos de Valencia desde el día 23 de mayo hasta el 28 de junio del año 1808. Valencia, MDCCCX. En la imprenta de Salvador Faulí. Con licencia; licencia; 106 páginas, 4.

13. Sor Inés. Novela instructiva. Valencia, por Francisco Brusola, 1815 ; en $8^{\circ}$

14. El joven René, traducido de la obra del Cristianismo de Chateaubriand. Valencia, por Salvador Faulí, $1817 ; 8 .^{\circ}$

15. Poesías. Valencia, por Ildefonso Mompié, $1818 ; 12 .^{\circ}$

16. Ververt o el Papagayo. Poema traducido del francés en verso castellano. Valencia, por Ildefonso Mompié, $1818 ; 12 .^{\circ}$ 
17. Reflexiones sobre las costumbres. Valencia, Imprenta de Francisco Brusola, 1818; en $8 .^{\circ}$ (dos tomos).

18. Exposición parafrástica del salmo 50, Miserere mei, Deus, útil a todas las personas que desean convertirse a Dios por una sólida penitencia, puesta en castellano, etc. Valencia, Faulí, $1809 ; 8 .^{\circ}$

19. Trabajos de Narciso y Filomela; a imitación del Persiles de Cervantes. Manuscrito.

20. La Ruperta, tragedia manuscrita.

Esta relación, debida al cuidado de Pastor Fuster, debe condensarse y agruparse por sus orientaciones; así, la número 1 está perdida según testimonio de los editores, como ya hemos dicho en su lugar. Las números $2,3,4,13$ y 19 constituyen el acervo novelístico de este religioso, y ea lo más inexpresivo de su labor; las numeradas con el 5, 6, 10 y 18 iniegran la producción ascética, perteneciendo al srupo de traducciones, en el que se unen a las 14 y 16 . La número 20 es única cuando de lo dramático se trata, y, por haber quedado inédita, ba pasado inadvertida para La Barrera y cuantos han tratado de nuestros poetas dramáticos; cuenta aparte hay que hacer del número 17 , que incorpora a este escritor al grupo de costumbristas. Mayor interés despiertan las obras designadas con los números $9,11 \mathrm{y} \mathrm{12,} \mathrm{de} \mathrm{índole} \mathrm{histórica.}$

Los editores de las Poesías las distribuyeron en dos partes: en la primera incluyeron las inéditas y en la segunda las ya publicadas. Cerraron el texto con la versión del Ververt o el Papagayo, traducido del francés. Tengo para mí ser más lógico tratar de fijar el orden cronológico de las composiciones, por lo cual, si hay la dificultad de carecer de datos fidedignos, hay también la ventaja de que la evolución se muestra muy unida a las circunstancias temporales.

Con este criterio ha de iniciarse el análisis con el de Reflexiones sobre las costumbres ${ }^{12}$, libro nacido al calor de las tertulias en que distraían al doliente escritor los amigos literatos o, al menos, filopoetas, dispuestos siempre a llevar a la celda del franciscano las novedades y habladurías de la ciudad. Por esta coyuntura son bastante artificiales las costumbres comentadas, y su ironía resulta de escasa eficacia.

A la cabeza de cada apunte figura un nombre muy rebuscado: Don Periandro; don Cleandro y doña Mencía; don Aristipo; don Eurípides;

12 El ejemplar 5-3113 de la Biblioteca Nacional está incompleto. Le faltan la portada y los preliminares del primer tomo, que termina en la página 392, con las signaturas $1-N$, de ocho hojas cada una, y el segundo tomo acaba en la página 126 , con las signaturas $\Lambda-R$, de ocho hojas, menos la última, que es de siete. 
don Teócrito; don Terencio; doña Teofanía; don Bías, etc., etc. Y seguidamente se acompaña un subtítulo que denuncia el vicio satirizado: el adulador; los dos monos; el iracundo, el orgulloso; los impertinentes; el sabio político..., siendo de notar la insistencia con que se recogen tipos relacionados con la política (junto al Bías, sabio político, se encuentra don Polidoro, el falso político) y se hacen múltiples alusiones a la materia. Se reiteran temas muy cultivados en la época. Recuérdese el mordaz cuadro de Goya en que refleja las circunstancias de una boda, y en el que la novia muestra su jactancia y se pavonea con el rico vestido, obsequio del estúpido novio; éste marcha detrás, poniendo en su rostro la clara prueba de su necedad y regodeándose con la pericia del sastre y lo selecto del llamativo casacón, mientras el cura marcha insensible a una situación de presente pregonera de la consecuencia futura. Cualquiera de las doñas Teágenes y Filomena podrían ser las novias, y don Peristilo y don Brontino los novios. No puede pensarse otra cosa, al oir la conversación entre las damas: "El se piensa que yo le he de querer por sola su figurilla, y que me pago de la retahila de requiebros que ha estudiado en algunas relaciones de comedias; pero se engaña: si esta noche no le saco para una grulleta, para unas mangas a la bombé, un monillo y unas blondas de tul y pantalones de punto con dedos, ahur, le despido per secula sin fin" ${ }^{\mathbf{1 3}}$. A lo cual opone su interlocutora que su don Brontino, "no un real mozo, pero sí un real viejo", le regaló "no más tarde que ayer"... "cuatro pares de medias de patente, otras cuatro a la cachucha, media docena de pañuelos imperiales, tres collares, uno de pelo, otro de coral y otro de ámbar, cada uno con su candado de oro; un vestido de corazón y tres pañuelos de gorguera; $\mathrm{y}$ lo mejor, doña Teágenes, es que nunca me faltan un par de onzas en el bolsillo").

La constancia en pedir toma caracteres crónicos cuando al hablar de los efectos del lujo se repiten, punto por punto, todos y cada uno de los objetos de la anterior relación con detalles de cierta mordacidad; pero el P. Colomer era moralista más que satírico. Por eso se basa en el Salmo 93 y en el libro de Job; recuerda palabras del P. Granada en su Guía de pecadores, de San Francisco de Sales y de Fray Luis de León y otros ascéticos y místicos. Ampliando su caudal erudito, cita a Cicerón, Rousseau, Boileau, Voltaire, etc.

Mayor interés que tales palabras reviste la obsesión manifestada siem. pre contra los libros franceses. Don Lisandro, o el viajero ilustrado, marcha a París y contempla lo baladí y externo; pero regresa creyéndose el más enterado y sabelotodo de cuantos han ido a Francia. Interviene en toda

13 I, pág. 116. 
conversación y "si hablaban de ciencias y de artes decía que España iba al menos un siglo atrasada; la Cirugía estaba en mantillas; la Medicina era poca cosa; poeta no había ninguno; historiadores, pocos y sin gusto ni crítica : sólo se conocía algún teólogo ramplón que sabía ergotizar. Pero es de advertir que el señor don Lisandro no tenía la menor idea de cirugía, ni de medicina, ni de poesía, ni de historia $y$, mucho menos, de teologían. "Doña Biblis, la pedantísima petimetra", se lamenta de las pocas obras de buen gusto que hay, y proclama: "Si no fuera por algunas traducidas del francés, estaríamos sin tener con qué nutrir el espíritu. Cierto que los franceses nos llevan mucha ventaja en todo. Si no fuera por ellos ni aun sabríamos cómo habíamos de vestir; en efecto, hasta de ahora las damas pareceríamos huevos en cáscara.) Y más adelante se dice : "Plugiere a Dios que tuviéramos el entendimiento aguzado siquiera para impedir la entrada de tantos libros infernales, $y$ ahorraríamos a tantos traductores el trabajo de darnos unos presentes tan funestos y de estropear la gala de nuestro rico y sonoro y fluido lenguage.) Insiste en su censura cuando en el tomo II se entabla la siguiente conversación: "Pero ¿tú sabes qué libros son los que don Galo le trae a la chica? -Cómo lo he de saber si yo no entiendo francés y hasta ahora son todos franceses los que ha traído, como que estaba aprendiendo esta lengua...) Y después añade: "Sacó don Protasio un legajo de libritos, y reconociendo don Cleóbulo sus títulos dijo: éste no respira más que obscenidades, y no como quiera, sino de lo más desenfrenado; éste no conoce distinción entre el vicio y la virtud; éste pone en duda cuanto la fe nos cnseña de premios y de castigos en la otra vida; este otro se burla de todo lo que pertenece a nuestra religión, pues cree que todas son buenas; este último se esfuerza por hacerse semejante a las bestias"; y anota : "Si yo escribiera aquí los títulos de tales libros, ¡ qué priesa se darían en buscarlos los pedantes libertinos como don Galo !)

Más interesante es la evolución experimentada en las poesías. En los primeros tiempos cultivó el tema puramente literario, con aspiración clásica, como el derivado de Catulo al pájaro de Lesbia; pero prefirió el lirismo de Meléndez Valdés dedicado a la paloma. Hay un marcado paralelismo entre ambos poetas. La estructura del primero se sustenta sobre cuatro columnas :

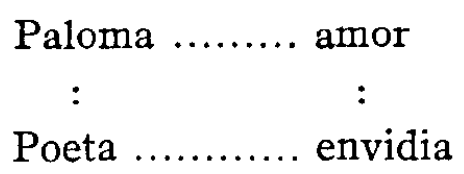

E1 P. Colomer convierte estos cuatro puntos de apoyo en los siguientes:

Jilguero jaula

Poeta celda 
Antes de sedimentar esta fórmula, titubearon los dos vates entre distintas tendencias. Fray Diego González, anotando la silva primera de Meléndez Valdés El Palomillo, la situaba en la línea del Pajarillo de Villegas, y, en efecto, el tema aislado tuvo un desarrollo profuso, y las palomas, desde el simbolismo bíblico hasta las inteligentes mensajeras, han tenido quien las cante en todo momento. Para el P. Colomer hay siempre un fondo optimista y esta condición se propaga al pajarillo que tiene un concepto grato de su jaula. La preferencia del jilguero sobre la paloma de Meléndez Valdés es natural y lógica: Batilo prefirió el álito erótico del arrullo que el ave dedica a Filis _primitivamente llamada Cloris-; Colomer elimina toda inclinación amorosa. No importa ahora el análisis de las Odas del extremeño; sólo interesa indicar la atención que les prestó el religioso valenciano. Este escribió ocho poesías sobre el tema, y, desde el principio, se puso de relieve el movimiento bascular que imperó en estas composiciones : a la situación del poeta corresponde la antiestrofa del pajarillo

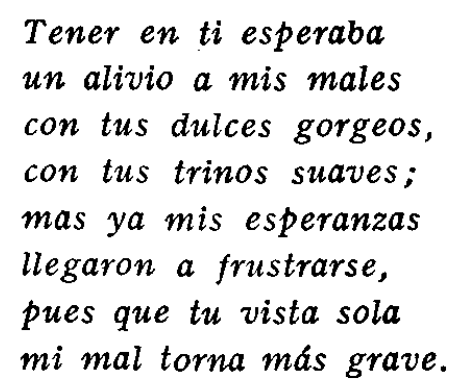

Para una identificación total de ambos escritores sería necesaria una unidad de naturaleza :

La pasividad doliente del valenciano contrasta con la actividad intensa del autor de La Flor del Zurguen. Los versos del religioso y los trinos del ave son líneas divergentes. El jilguero está alegre, mientras el religioso desea dominar su angustia. Este, buscando la calma, recuerda los días felices de la libertad, cuando, de rama en rama, volaba el ave atraída por 
otra que le invitaba a gozar del campo y de la vida. E1 poeta se queda al margen, y se centra el comentario exclusivamente sobre la enjaulada pajarilla, la cual volaba antaño

.. hasta que, cuitadilla,
te paras en un ramo
do presa en blanda liga...

es cazada con argucia y maldad, impedida de surcar el espacio con su gracioso y corto vuelo. Pero la transición es radical: nada importa lo pasado :

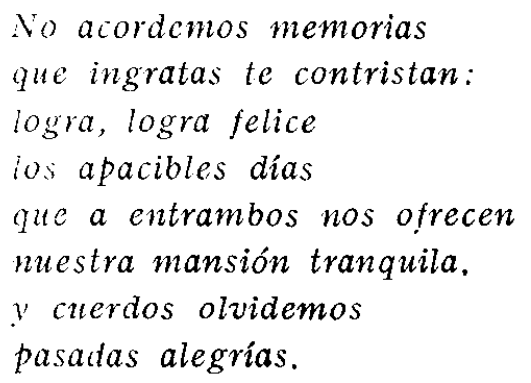

Poeta y jilguero van haciéndose convergentes: la jaula privará de libertad, pero evitará los peligros de la vida, porque el gavilán acecha y destruye al pajarillo que, cándidamente, vuela de árbol en árbol, y desprecia la invitación del dueño para que se lance al campo y
a tu estilo me dices
ion delicados trinos
la libertad no quiero
màs dulce es mi retiro.

Es el religioso el que aprende: la libertad tiene sus peligros :

$$
\begin{aligned}
& \text {.. a mi conducta } \\
& \text { le servirán de regla } \\
& \text { y con fijo cuidado, } \\
& \text { atento siempre a ellas, } \\
& \text { haré que mis placeres, } \\
& \text { mis risas y mis fiestas, } \\
& \text { mis glistos y mis glorias } \\
& \text { se cifren en mi celda. }
\end{aligned}
$$

Pasadas las horas felices, resulta más honda la compenetración entre los dos seres; pero también se hace más patente la diferencia de aquello 
que les rodea : la fragilidad de la jaula se acentúa ante la solidez espiritual de la celda; esta divergencia desemboca en el choque de nada contra eternidad:

$$
\begin{aligned}
& \text {..tú, a la nada; } \\
& \text { yo, a los años eternos, } \\
& \text { partamos de esta vida } \\
& \text { cuando lo ordene el cielo. }
\end{aligned}
$$

Ratifica el valenciano el triunfo de la celda como mansión de paz y de alegría. A ella se dirigió quien vio en el mundo tanto, i tanto!, que decidió gustoso retirarse

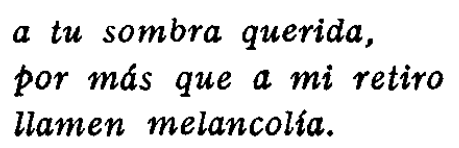

Las influencias de los poetas de la época tienen el interés propio de las orientaciones que inspiraron; pero Martínez Colomer no dejó de imprimir carácter a su obra, reflejo exacto de su temperamento y circunstancias relevantes de su vida. Cuando prescinde de su biografía busca algún rasgo de la literatura patria y alza su bandera en favor de aquellas joyas medievales, como las del Marqués de Santillana; en la oda La caída de Lenio atiende una zagaleja al distraído joven caído en un arroyo, y cuando él le ofrece su mano, ella vuelve las espaldas diciendo: "Me voy a mi ganado.) Es fácil encontrar antecedentes a la temática del $\mathrm{P}$. Colomer : A una abeja, $A$ una hormiga, A la cigarra; a veces con sentido irónico. Abuso de invocar a las musas en cualquier asunto, donde escribe :

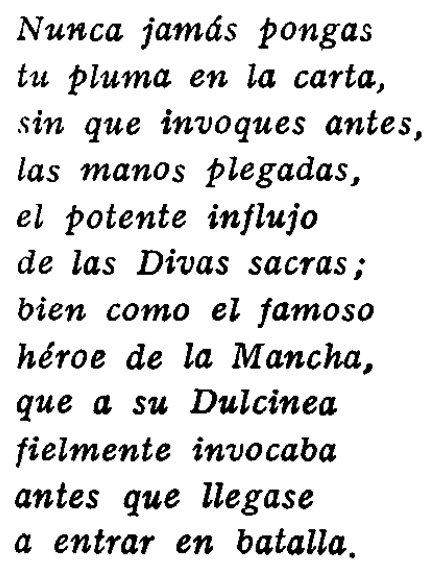

La intimidad del franciscano inspira el fragmento de la letrilla Las alabanzas de los aduladores no engrandecen. 


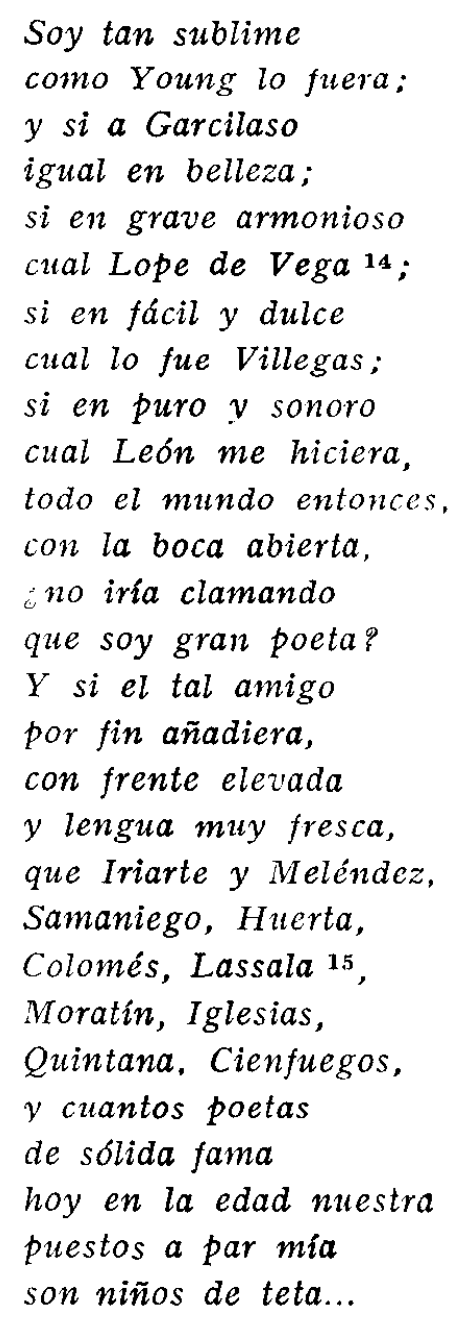

Obsérvese que no aparece ningún escritor francés, y respecto de los ingleses solamente figura Young, haciendo pensar que el verdadero recuerdo lo suscitaba Cadalso, aunque no aparezca taxativamente expreso. Todas estas bagatelas líricas dejan paso a temas religiosos, latentes en cuanto se debe a la minerva del valenciano. La Letrilla a un Niño Jesús muy hermoso, con el estribillo que no sé qué tengo-desde que te vi; el romancillo $A$ Filotea; el dedicado a una religiosa al contemplar la pequeña iglesia de San José de Avila, donde su seráfica Madre Santa Teresa fundó el primer convento de su Orden; las liras $A$ la temeridad del

14 Obsérvese la inclusión del nombre de Lope, tan olvidado en Valencia durante la centuria decimoctava. Vid. Preferencias del público valenciano $\bullet n$ el siglo XVIII, RFE, 1933.

15 La ingerencia de estos escritores jesuitas, cuya vida transcurrió muy singularmente en Italia, se explica por tener una fama extendida por el ámbito local y durante un tienıpo escaso. La Barrera no recoge las obras dramáticas que escribieron. 
pecador, y los endecasílabos libres $A$ una imagen del Patriarca San Francisco que tiene el autor, grabada por el célebre Claudio Mellán, son el caudal devoto creado por el P. Martínez Colomer, aunque es de advertir que deben agregarse las versiones de textos bíblicos, como la parafrástica del Salmo De profundis, el Cántico de Habacuc, el Cántico primero de Moysés, A la soberbia, en las que asoma la influencia de Herrera, no siempre inconcusa, por ser probable se trate de semejanzas debidas a fuentes comunes, o sea la Biblia, y no a la obra del poeta sevillano.

Llegados a este punto, se abre ante nosotros el mayor intento acometido por el escritor de Valencia. Hasta aquí vivió inmerso en el siglo XVIII : sus lecturas de tiempos anteriores calaron poco en la entraña de su estética; empero, cuando alboreaba el XIX, se produjo en nuestro poeta la reacción natural debida a los acontecimientos históricos; ellos enmarcaron a los escritores valencianos con signos contrapuestos. Los primeros días del siglo XVIII dividieron al pueblo español en dos sectores: los entregados a los Borbones, que se extendían por el centro y oeste de la Península, y los secuaces del Archiduque de Austria, quienes ocupaban el Levante español. Los literatos formaron en ambos bandos: los afrancesados asimilaron las corrientes ultrapirenaicas, y los seguidores de Carlos sintieron el latigazo de la supresión de los Fueros con dolor prolongado durante la centuria y aun en la siguiente. Caso como el del toledano Gerardo Lobo es una excepción debida al temperamento satírico del capitán de guardias más que a manifestación política antiborbónica. Creo muy digno de nota el análisis de las reacciones producidas en los escritores por la decisión de Felipe $\mathrm{V}$ en 1707. En otra ocasión me he ocupado de la situación creada por la ideología política de Mayans y Siscar, incompatible con sus servicios en la Biblioteca del Rey, por ser la familia del hijo de Oliva afiliada al Archiduque; ha de olvidarse la leyenda del carácter envidioso y violento del erudito y destacar el propósito de aislarse junto al Mare Nostrum a fin de evitar los conflictos familiares derivados de encontrarse algunos parientes encarcelados, mientras él vivía disfrutando de las ventajas de su cargo ${ }^{16}$.

En los días en que Martínez Colomer sentía el tema de la Patria como acicate para la inspiración, proclamaba el Conde de Noroña normas estéticas que pretendían borrar lo que había sido imitado largamente. Impresionado por las Poesías asiáticas, conocidas al través de versiones inglesas, recomendaba: "Me prometo que los amantes de la verdadera poesía distinguirán estas composiciones llenas de fuego e imágenes pintorescas de las insulsas filosóficas prosas rimadas que nos han venido de algún tiempo

16 Cfr. Anales del Centro de Cultura Valenciana, 1952, XIII, págs. 814 a 332. 
acá de allende de los Pirineos, vendiéndonoslas como buena mercancía. Los genios españoles, que tanto han brillado por su fecunda y hermosa imaginación, deben abandonar esas gálicas frialdades, y no desdeñarse de leer los poetas del Oriente, en quienes todo es calor y entusiasmo y entre los cuales suenan con honor algunos hispanos, cuyas obras yacen sepultadas en E1 Escoria1.) Resulta difícil demostrar la influencia de poetas franceses sobre el castellonense, como se ha pretendido en alguna ocasión, después de este repudio tan tajante.

Años más tarde, ya mediado el xIx, dedicaba don Vicente Boix sus diatribas contra la determinación del primero de los Borbones ${ }^{17}$.

Constantino Llombart lanzó a los cuatro vientos su libro Los Fills de la morta viva, y forman legión aquellos que afilaron su pluma para rererdecer la cultura valenciana por aquellos tiempos.

En un momento especial encontramos al P. Vicente Martínez Colomer, quien contemplaba siempre la vida valenciana desde su atalaya. La ciudad se llenó de fiesta para recibir a Carlos IV y María Luisa. Había vibrado ya otras veces: para la boda de Felipe III con Margarita de Austria, días en que Lope de Vega anduvo de botarga y no dejó en paz a su fecunda pluma, y en los que Guillén de Castro cultivó la comedia de costumbres con La verdad averiguada y engañoso casamiento, y, sin tanto boato, otra vez cuando Felipe V, Isabel de Farnesio y el príncipe Luis no encontraron obstáculos que demostraran inquina popular por la supresión de los Fueros decretada doce años antes.

17 Recuérdense particularmente las poesías El poeta y la sombra del Rey don Jaime y Al Miguelete, al que dice:

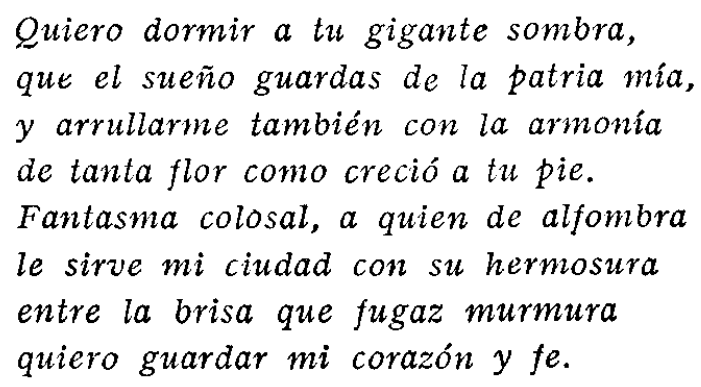

A su vez decía dirigiéndose $A l$ antiguo pendón de Valencia:

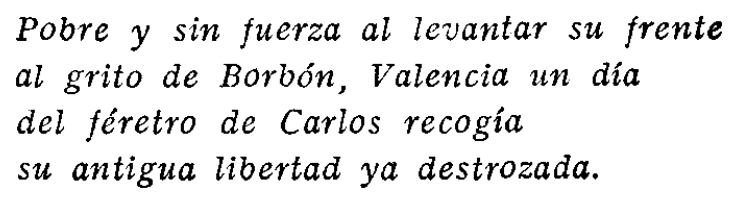


El franciscano dedicó seis odas para saludar a los monarcas en 1802, "cuando los Reyes padres vinieron a esta Ciudad". En ellas puso de relieve su cortesanía sin lograr matices ciertamente poéticos.

Empero, llegado el año 1808, "cuando los franceses se llevan traidoramente a nuestro Soberano Fernando VII", el Padre Colomer sintió que su estro tomaba forma y consiguió algunas estrofas dotadas de aliento y vigor no alcanzado hasta entonces :

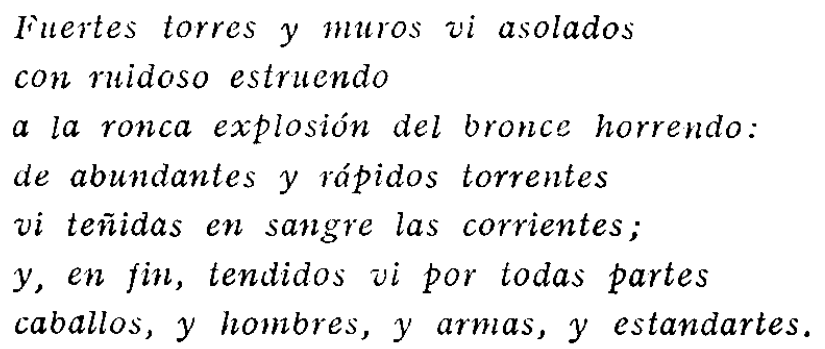

E1 año siguiente escribió La España vencedora, puesta en la misma línea que la anterior; se solaza en la paz bucólica para buscar el contraste bélico :

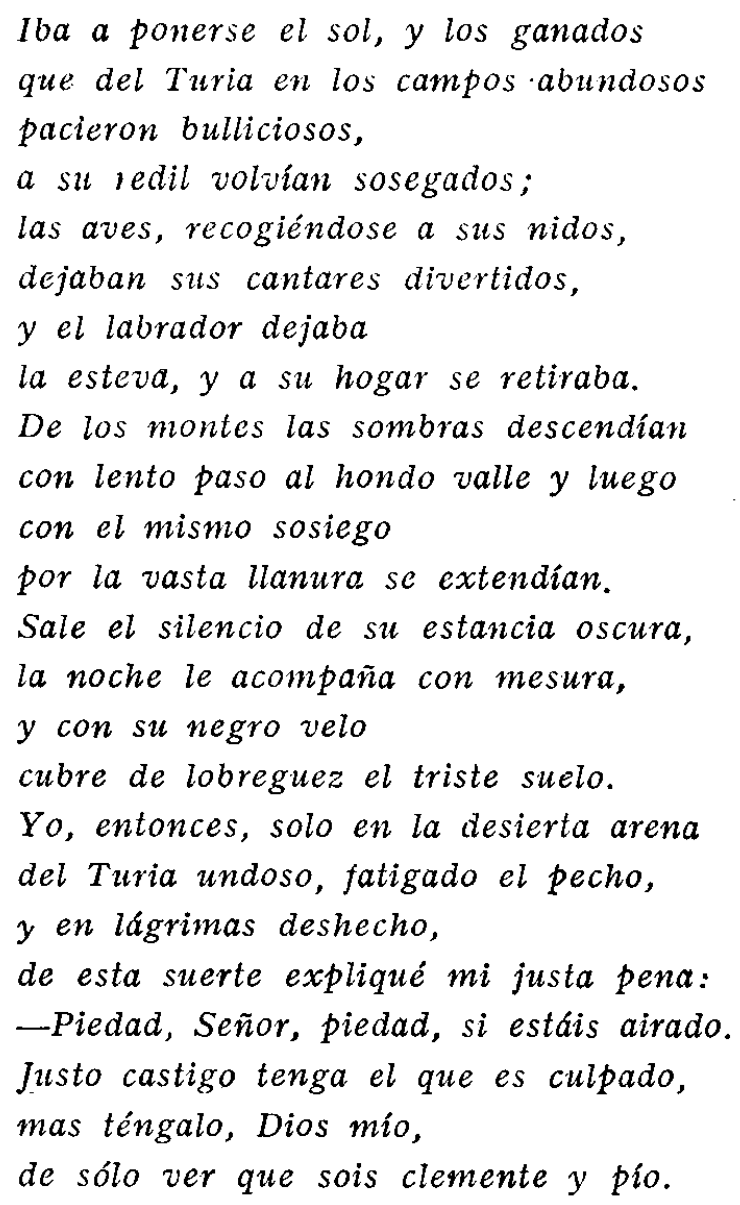


Una ráfaga de dolor rompe la tranguilidad campesina, y el pocta tienc rasgos ąue recuerdan estrotns de don Juan Nicasio Gallego.

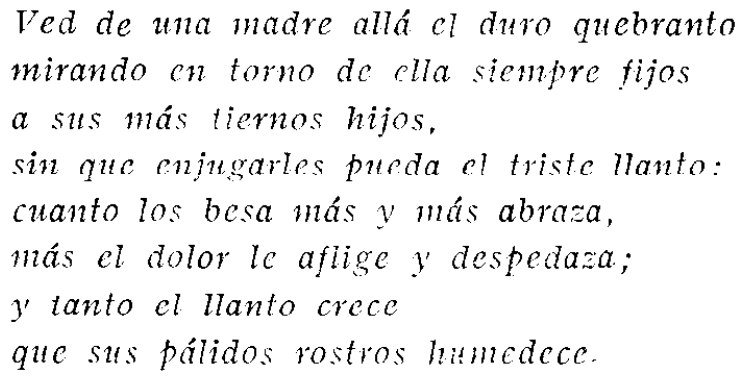

Con tolo, la eweranea es at sello ane pone el religioso para dominar el terror y la tiranía:

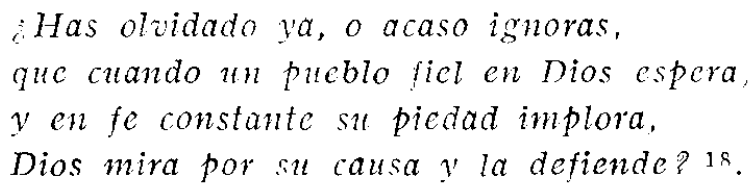

E1 religioso se sobrepone a! poeta, y si el verso se debilita, la reflexión orienta con mayor insistencia cada rez:

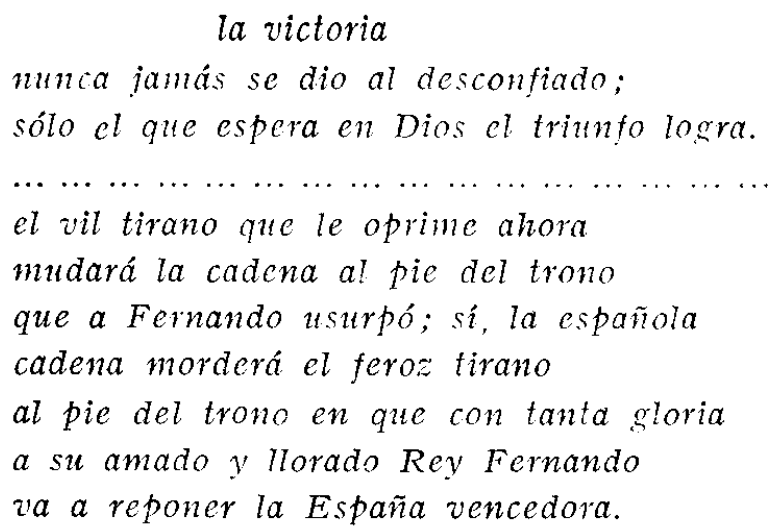

Cada vez limita más el tema, y así, en 1809. entona su cántico en honor del Marqués de la Romana por su odicea desde Dinamarca para incornorarse con su ejército al ejército nacional; en 1811, exalta el nombre de Manuela Morcilla, viuda de Vicente Sancho, y, más tarde, torna a recoger en cuatro odas la erección de una estatua en honor de Fernando VII,

18 El Marqués de VALMAR cita esta estrofa como de «inspirados rersos». 
ocasión aprovechada para recordar las horas trágicas y soñar un porvenir de felices augurios:

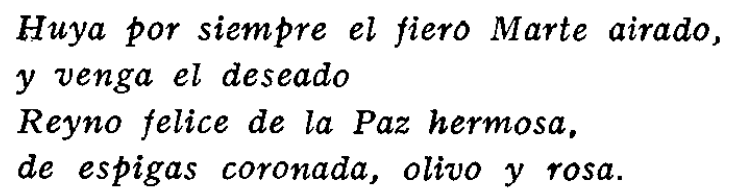

La traducción del Vertvert es un episodio carente de interés, tanto por el fondo como por la forma, sin que ofrezca motivo de atención la posibilidad de fijar la cronología de esta versión y, por tanto, su relación con el resto de la producción versificada del Padre Martínez Colomer.

Los hechos cambiaron el rumbo literario del poeta, quien a fuerza de querer ser sencillo resultó prosaico con demasiada frecuencia. La apacible celda era ambiente de serena reflexión. El moralista tendía su arco y disparaba sin ira, y cuando la dolencia le recluyó con la ventana abierta para ver el campo y el cielo, se sintió compensado con los relatos de los que le acompañaban frecuentemente, ya seglares, ya hermanos de Religión, los cuales marchaban con frecuencia hacia la ciudad. Dos conventos de Menores había en Valencia : el de San Francisco, que podía mantener de 100 hasta 104 religiosos, y el de Jesús, donde moraba Colomer, con capacidad y economía aptas para sustentar de 70 a 74 . Por encontrarse extramuros, hubo que dictar algunas normas para evitar abusos, y así se ordenó "que en el Convento de Jesús se reglasen de manera las salidas de los religiosos a decir Misa en los días festivos que se reservasen ocho, a lo menos, para que los servicios de la Comunidad se cumplieran debidamerite, y para que las personas del siglo que acudieren a la iglesia pudieran encontrar el alivio espiritual. Que en los demás días no se permitiera salir a ningún religioso, a menos que alguna precisa necesidad la obliga se; y aun en este caso se le diese licencia por la tarde, porque por la mañana siempre parecen odiosas las salidas" ${ }^{19}$. Estas circunstancias hicieron que el P. Colomer estuviera informado de cuanto ocurría en Valencia durante los días de $\mathbf{1 8 0 8 .}$

Siguiendo su sistema de amenizar los hechos con rasgos novelescos, inició su interpretación de la caída de Godoy y los sucesos madrileños con su lucubración El Filosofo en su Quinta o relación de los principales hechos desde la caída de Godoy hasta el ataque de Valencia, donde acumuló

19 Historia de la Provincia de Valencia de la regular observancia de San Francisco, por el P. Fr. Vicente Martínez Colomer. Valencia, por Salvador Faulí, año 1803, tomo I (ánico publicado), pág. 382. 
adjetivos y odios desconocidos en los escritos anteriores. Consignó detalles de la lucha merced a las fuentes valiosas en que bebió para redactar su obra : "Se callan -dice- los nombres de los sujetos que concurrieron a todas las escenas de este acto, porque el que me lo contó no sabía si todos gustarían de que se publicasen: unos por modestia y otros por el oprobrio ( $s i c$ ) que podría resultarles.) Con espíritu moderno prefiere destacar el carácter de los testigos al simple relato de los sucesos. Tiene buen cuidado de fijar el paradero de la documentación en que se basa : respecto al oficio de don Vicente Moreno, firmado "Comandante del Pueblo Soberano" a fin de pedir fondos al Cabildo catedralicio para sufragar los gastos de la lucha, indica: "existe en el Archivo de esta Catedral". Juan Bautista Perales, en su continuación de las Décadas de Gaspar Escolano ${ }^{20}$, confiesa haberse fundado en el sin número de relaciones escritas y publicadas sobre aquellos sucesos que presenció el $P$. Colomer, y en cuya relación, "que es la que ha servido de guía a todos los que de este asunto han escrito de entonces a hoy"... Sin embargo, el propio franciscano declara : "En un asunto tan delicado como el que voy a tratar, no he querido exponer ningun hecho sin apoyarlo sobre fundamentos incontrastables. Tales son los sugetos (sic) que cito, que viven todavía, que fueron testigos de vista, y cuyas relaciones firmadas de su mano existen en mi poder." Sabemos también, por los editores de las Poesías, que era precaria la salud de Colomer, lo cual le obligaba a recluirse en su celda y ser allí visitado por amigos y hermanos de Religión. Sus testigos colaboraron con su acción a los incidentes más destacados de aquellas fechas. Don Lorenzo Pérez, graduado de subteniente de Artillería, y Francisco Domingo, sargento del mismo cuerpo; el P. Vicente Juan, dominico; el P. Igual, lector de Prima y Doctor de Teología en la Universidad valenciana; el P. Mariano Ribera, lector de Prima, del Convento de la Corona ; los PP. Felipe López y Andrés de Vera, religiosos mínimos; el pregonero Francisco Amorós, y otros, entre los que abundan, como es natural, los franciscanos, constituyeron el cimiento de esta obra. ¿Fue en el convento de Santa María de Jesús o, por estar extramuros, pasaría el escritor al de San Francisco, en el interior de la ciudad? A este convento pertenecían los PP. Rico y Martí, actores destacados de gran parte de aquellos hechos y el primero autor de unas interesantes Memorias. No figuran éstos en las listas de in-

20 Décadas de la Historia de la insigne y coronada ciudad de Valencia, por don Juan B. Perales. Tercera parte. Continuación de las Décadas que escribió el licenciado y Rector GaSPar Escolano. Valencia-Madrid, Terraza, Aliena y Compañía, 1889, tomo III, pág. 971. 
formantes, lo cual parece indicar que Colomer continuaría en su residencia habitual.

No nos incumbe el estudio del relato en sí, labor que atañe a los his. toriadores; interesa aquí, solamente, observar la diferencia de método entre las poesías, las obras en prosa de la juventud y estas páginas elaboradas sobre un tema vivo y candente. Antaño se sobreponía el escritor a lo escrito, y los versos de inspiración lírica, producto de lecturas, se adaptaban a situaciones personales intrascendentes. Ya en el siglo XIX se impuso la realidad y lo objetivo arrastró al literato. En este caminar desarrolló una ideología ajena a los problemas cultivados por gran parte de los escritores del siglo xvrr. La abolición de los Fueros no hirió la sensibilidad del P. Colomer, para quien Felipe $\mathrm{V}$ quedó sumido en el olvido, y puso toda su atención sobre los Borbones de principios del xIx, en quienes se encarnaban las tendencias populares del siglo XvIr referidas a los Austrias y sintetizadas por Calderón de la Barca en los cuatro conocidos versos de $\mathrm{El}$ Alcalde de Zalamea. Esto desvió la protesta e incubọ la censura contra la inmoralidad procedente del otro lado de los Pirineos. Precisamente resultó trastocada la situación en los primeros años del siglo XIX con relación a los del anterior : en éste, era Francia la que desplazaba al austríaco; cien años más tarde pugnaba la nación gala por eliminar a la dinastía implantada por ella. La celda se estremeció ante el espanto callejero y el estruendo de los cañones y la fusilería. Mucho contribuyó la celda a dotar de ecuanimidad al relato de las impresiones de las jornadas luctuosas. Muchas páginas acogieron a las contiendas por la Independencia española : en la Biblioteca Pública de Toledo se conserva un manuscrito anónimo que acentúa la violencia de las escenas; el P. Colomer rehuye detenerse en detalles de venganzas y de asesinatos. El poeta suave, el costumbrista a quien duelen sus propias ironías, el cronista agotador de los recursos informativos y claro expositor de lo acontecido, toda la gama de las actividades del religioso franciscano palidece ante las páginas sinceras en que se vierte lo ocurrido en Valencia en 1808. El libro se cierra con aires de victoria: "Así derrotó Valencia delante de sus muros al Exercito aguerrido del Mariscal Moncey y ahuyentó vergonzosamente las débiles reliquias que le quedaron." $\mathrm{Y}$ transcribe las leyendas de las lápidas puestas en la puerta de Cuarte para constancia de los sucesos...

Bajo los auspicios del triunfo compuso, en 1809 , las ya mencionadas poesías dedicadas al Marqués de la Romana y a la España vencedora; el P. Colomer, terminada su labor histórica, quiso poner a su espejo las 
galas de la poesía. Y cantó con las palabras más anargas que pueden encontrarse en sus cscritos, e increpa a Napoleón:

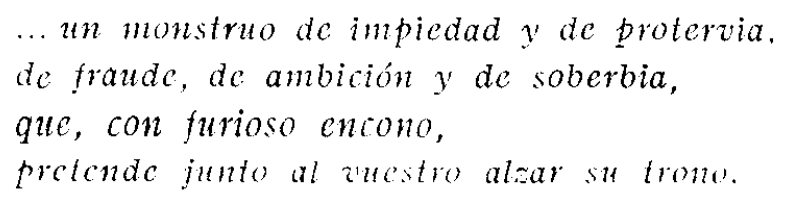

Este grito de combate tiene su paliativo en la piedad puesta al servicio de la salvación de los franceses indefensos, sacrificados entre los arrebatos de ira tan frecuentes, por desgracia, cuando acometen las nuchentunlics. Llombart tiene un gesto de duda al referirse a la conjuración del canónigo Calbo: el P. Colomer se hace eco de los esfuerzos que se realizaron para evitar se tratase como a enemigos a los que sólo tenían la angusia de estar privados de la libertad.

$$
\text { Iíduardo JUlá MarTícì }
$$

